\title{
Thermal, electrical, mechanical and fluidity properties of polyester-reinforced concrete composites
}

\author{
BARIŞ ŞIMŞEK ${ }^{1, *}$ and TAYFUN UYGUNOĞLU ${ }^{2}$ \\ ${ }^{1}$ Department of Chemical Engineering, Faculty of Engineering, Çankırı Karatekin University, 18120 Çankırı, \\ Turkey \\ ${ }^{2}$ Department of Civil Engineering, Faculty of Engineering, Afyon Kocatepe University, 03200 Afyon, Turkey \\ e-mail: barissimsek@karatekin.edu.tr
}

MS received 14 March 2017; revised 8 August 2017; accepted 19 October 2017; published online 13 April 2018

\begin{abstract}
Polyester particles in concrete are preferred because they provide thermal, chemical and water resistance. In this study, thermal conductivity, electrical resistivity, mechanical strength and water resistance properties of concretes containing polyester granules such as flame-retardant polyester, cationic dyeable polyester and polyester with a low melting point-filled concrete have been analyzed using a full factorial design via Minitab ${ }^{\circledR}$ version 17 . The effect of the most influential factors on thermal conductivity of polyester aggregate reinforced concrete composite has been determined as an interaction between the cationic dyeable and lowmelt-point polyester. This mixture is suitable for production of thermal insulating concrete. Moreover, it is concluded that cationic dyeable polyester is the highest corrosion- and water-resistant product among the polyesters used in this study. The recovery rate of $33.94 \%$ in the thermal conductivity and $214.89 \%$ in the electrical resistivity of polyester-reinforced concrete composites has been obtained with a 28-day compressive strength loss of $41.94 \%$ according to the reference concrete in the full factorial design application. These results indicate that the polyester-reinforced concrete composites are quite effective in achieving thermal and corrosion resistance concrete but with noticeable compressive strength loss.
\end{abstract}

Keywords. Design of experiment; electrical resistivity; polyester-reinforced concrete composites; thermal conductivity; product design.

\section{Introduction}

In recent years, polyesters have been widely used in resin systems to provide extraordinary mechanical [1], corrosion and water resistance properties to composite materials [2]. These properties of the polymerised polyester resins make it an attractive material in the field of civil engineering application [3, 4]. Inorganic fillers such as cement, sand, silica fume and fly ash, granule blast furnace slag have been incorporated into polyester resins to improve some physical and mechanical properties of concrete composites [2]. Many researchers have investigated polyester resins reinforced concrete properties such as thermal stability and elastic modulus [2, 5], ultrasonic pulse velocity [6], compressive and flexural strength [7, 8], thermal expansion [9], chemical resistance [10], abrasion resistance [11], thermal conductivity [12], tensile strength [13], durability [14], and morphology [15]. Many of these studies have focused on one or two properties of polyester-reinforced concrete composites (POREC) just as mechanical, thermal or water resistance. However, critical evaluation of all the properties

*For correspondence of POREC simultaneously is necessary for real-world applications. In industry, a product is evaluated with multiple features such as thermal, mechanical or workability. In order to get the desired quality of POREC, a systematic analysis approach containing a design of experiment (DoE) methodology has been proposed in this study. The main contribution to the study is that thermal, electrical, workability, mechanical and water resistances of three different types of polyester-reinforced concrete composite have been analyzed simultaneously through full factorial design. Thus, the study aims to explore the effect of polyester granules on concrete using DoE approach.

Polyester resins, which are commercially available in various products with the fillings, fibers and granules [16], are produced with different features such as low melting point for fabrics, which are especially used in the automotive industry [17]; flame retardant for the clothing industry [18]; or fabrics used in the transportation vehicles; and cationic dyeable for the textile industry [19]. Most of researchers have focused on synthesis of polyester with different features. This paper aims to reveal the effect of low melting bonding, flame retardant and cationic dyeable polyester granules properties on concrete composites. Thus, 
Table 1. The properties of the polyesters use in this study.

\begin{tabular}{|c|c|c|c|c|}
\hline \multirow[b]{2}{*}{ Properties } & \multicolumn{3}{|c|}{ Values } & \multirow[b]{2}{*}{ Standard } \\
\hline & FRP & $\mathrm{CDP}$ & LMP & \\
\hline Elongation at break, $\%$ & $15-30$ & $15-30$ & $15-30$ & ISO 527 \\
\hline Specific gravity & $1.35-1.40$ & $1.35-1.40$ & $1.35-1.40$ & ISO 1183 \\
\hline Tensile strength, $\mathrm{MPa}$ & $40-45$ & $40-45$ & $35-40$ & ISO 527 \\
\hline Tensile modulus, GPa & $1-2$ & $1-2$ & $1-2$ & ISO 527 \\
\hline Hardness, Shore D & $70-75$ & $75-80$ & $75-80$ & ISO 868 \\
\hline Flexural strength, $\mathrm{MPa}$ & $40-45$ & $40-45$ & $35-40$ & ISO 178 \\
\hline Thermal conductivity, $\mathrm{W} / \mathrm{m} * \mathrm{~K}$ & $0.2-0.3$ & $0.2-0.3$ & $0.2-0.3$ & ASTM D5930 \\
\hline Electrical resistance, ohm-m & $10^{8}-10^{10}$ & $10^{8}-10^{10}$ & $10^{8}-10^{10}$ & ASTM D257 \\
\hline Purity, \% & 100 & 100 & 100 & N/A \\
\hline Granule size, $\mathrm{mm}$ & $0-4 \mathrm{~mm}$ & $0-4 \mathrm{~mm}$ & $0-4 \mathrm{~mm}$ & N/A \\
\hline Granule type & Cylindrical & Cylindrical & Cylindrical & N/A \\
\hline Granule color & Dark grey & Smoky & Beige & N/A \\
\hline
\end{tabular}

the application areas of these polyester aggregates in the construction industry will become clearer via this research. Moreover, the electrical resistance performance of polyester granules in concrete has not been considered yet in the previous studies. In this respect, it is important for manufacturers to evaluate the performance in concrete. This study provides information to researchers and plastic manufacturers about how to dispose of these polyesters wastes in concrete manufacturing industry.

Polyesters in concrete are preferred because they provide thermal insulation in terms of saving energy, providing water resistance and reducing the compressive strength of the concrete. The study aims to reach the desired level of heat and electrical insulation at an acceptable level of compressive strength using experimental full factorial design. It is important to identify the factors affecting the quality of concrete in designing innovative material and product design. The present study also aims to expose the binary interactions among polyester on concrete properties using Pareto effect analysis based on the full factorial design.

First, the effect of the factors and their levels on the electrical, thermal, workability, water resistance and mechanical properties of polyester aggregate mixed concrete have been defined. Then, the experiments have been carried out according to the runs determined by full factorial design. The resulting properties have been analyzed systematically by analysis of variance.

\section{Materials and method}

\subsection{Materials}

Portland cement has a specific gravity of 3.14 and Blaine fineness of $3584 \mathrm{~cm}^{2} / \mathrm{g}$. Class F-type fly ash with a specific gravity of 2.48 and Blaine fineness of $3812 \mathrm{~cm}^{2} / \mathrm{g}$ have been procured from Zonguldak Çatalağzı thermal power plant. Polycarboxylate ether-based super plasticiser (SP) has been used in all concrete mixtures. Fine aggregate of a size smaller than $4 \mathrm{~mm}$ and coarse aggregate (I) of a size between $4 \mathrm{~mm}$ and $11 \mathrm{~mm}$ and coarse aggregate (II) of a size between $11 \mathrm{~mm}$ and $22 \mathrm{~mm}$ have used in concrete mixtures. The fine and coarse aggregates have specific gravities of 2.69 and 2.81 and the mean water absorptions of $1.46 \%$ and $0.89 \%$, respectively. Polyester granules such as flame-retardant polyester (FRP), cationic dyeable polyester (CDP) and polyester with the low melting point (LMP) have been supplied from a company operating in the engineering plastics production. Their properties are given in table $1[20,21]$.

\subsection{The full factorial design and Pareto effect analysis}

The experimental design techniques play an important role in developing a new process and enhancing product performance. The objectives of the experimental design applications can be summarised as identifying the most effective input factors on the quality characteristics and determining the factor levels which can optimise the quality characteristics.

Interaction effects of factors can be investigated with the help of full factorial designs [22]. The factorial design consists of all possible combinations of all levels of each factor in the experiment. The most important advantage of full factorial experiment designs is that the main and interaction effects of the factors on the quality characteristics can be measured and analyzed easily via the experiment design method. The Pareto charts obtained by the full factorial design provide information about the magnitude and significance of a factor's effect [23]. These charts show the absolute value of the effects and the 

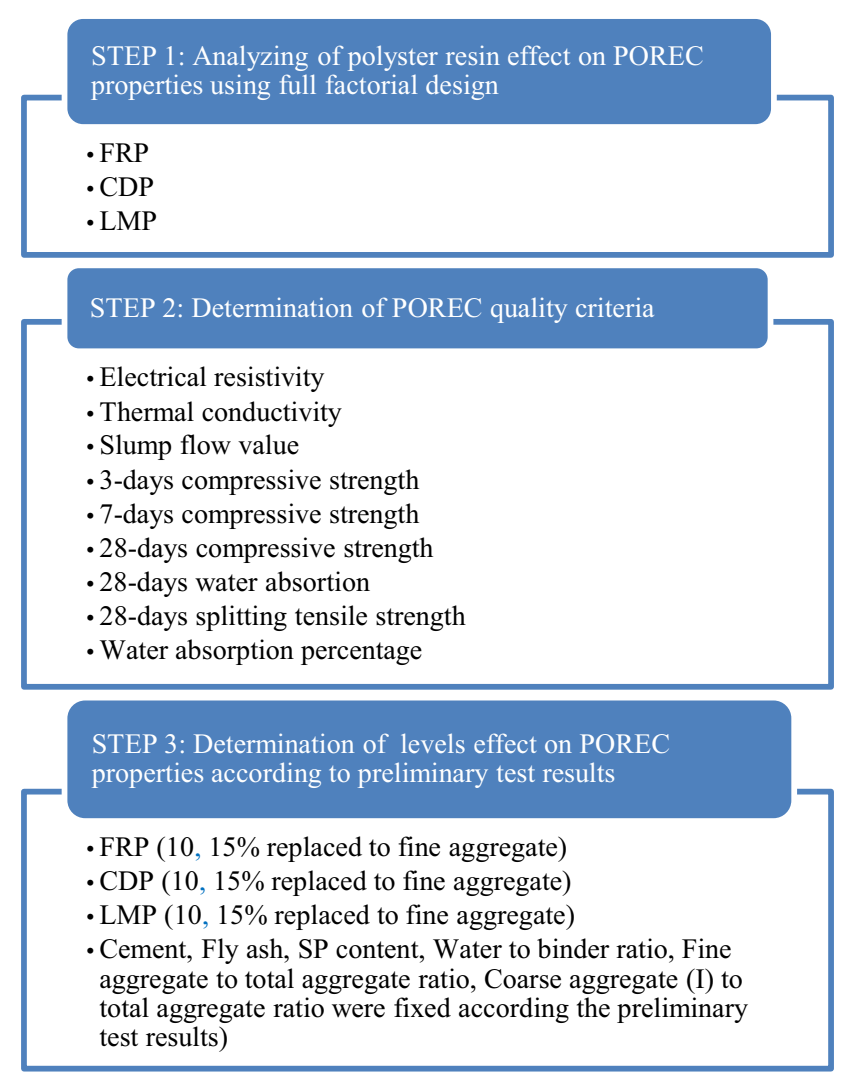

STEP 4: DESIGN OF EXPERIMENT VIA FULL

FACTORIAL DESIGN

- Implementation of design

- Obtain experimental results

STEP 5: ANAYSIS OF POLYESTER RESINS EFFECT ON

CONCRETE

- Main effect plots

- Interaction effect plots

Figure 1. Proposed methodology for analyzing polyester-reinforced concrete composite properties.

importance of the factors can be evaluated using absolute values. Moreover, a Pareto chart is an effective tool that helps us identify the variance source, and thus it is possible to design a product with the desired quality characteristics. A Pareto chart based on full factorial design, which is a simple statistical tool, can also be used to analyze and sort the individual, two-way and three-way interaction effects.

\subsection{Methodology}

Factor analysis of the polyester-reinforced concrete composites includes five flow steps (figure 1). First, electrical resistance, thermal conductivity, slump flow, 3-day compressive strength, 7-day compressive strength and 28-day compressive strength, the 28-day splitting tensile strength and the percentage of water absorption of hardened concrete have been determined as POREC quality criteria. FRP, CDP and LMP have been replaced in $0-4 \mathrm{~mm}$ fine aggregate, which is defined as the factors' effect on POREC properties. POREC properties have been determined by the full factorial design-based DoE approach. Finally, Pareto charts and main effect plots, which are obtained with the full factorial design, have been used to analyze the importance levels of factors.

\section{Identifying performance optimisation properties of POREC}

\subsection{POREC's performance criteria}

Thermal conductivity selected as the first criterion provides information on the heat loss between an environment and building $[24,25]$. Using concrete with low thermal conductivity in buildings provides the thermal comfort for residences and energy savings for manufacturers. TCIThermal Conductivity Analyzer was used in the study to determined the thermal conductivity of concrete by hot wire method as given in ASTM C 1113 standards [24, 26].

Electrical resistivity of concrete is affected by the pore size distribution and interconnection, degree of saturation, conductivity of pore fluid and temperature. The two methods of probe are a simple yet reliable as they measure the bulk electrical resistivity in laboratory-based quality control tests. The same concrete specimens, which are prepared for the physical and mechanical tests, can be used for resistivity measurement. In the measurements, the concrete sample is placed between two parallel metal plates with moist sponge contacts at the interfaces to ensure proper electrical connection.

A DC current is applied, and the resistivity of concrete between electrodes is measured on the dry specimens. The two-probe method is used to determine the POREC electrical resistivity and all measurements are carried out at room temperature [27]. Electrical resistivity of POREC is calculated as follows [27]:

$$
\rho=\frac{R S}{L}
$$

Where $\rho$ is the electrical resistivity as $\Omega . \mathrm{m}$; the internal electrode distance is symbolised as $L(\mathrm{~m})$; the electrode conductive area is defined as $S\left(\mathrm{~m}^{2}\right)$ and $R$ is the measured resistance as $\Omega$ [27]. Electrical resistance values also give information about corrosion risk [28]. High electrical resistance means low corrosion risk and high corrosion endurance [28].

The 3-, 7-, 28-day compressive strength of POREC was determined according to the EN 12390/3 [29]. The 28-day splitting tensile strength of POREC was also determined by the EN 12390/6[30]. Slump flow value, the percentage of water absorption POREC was determined according to EN 
Table 2. POREC characteristics.

\begin{tabular}{lcccc}
\hline Quality criteria & Exemplar & Definition & Type of concrete test & Desired properties \\
\hline 1 & R1 & Thermal conductivity $(\mathrm{W} / \mathrm{m} \mathrm{K})$ & Hardened concrete test & Minimise \\
2 & $\mathrm{R} 2$ & Electrical resistivity $\left(\mathrm{ohm} \mathrm{m}^{*}\right)$ & Hardened concrete test & Maximise \\
3 & $\mathrm{R} 3$ & Slump flow $(\mathrm{cm})$ & Fresh concrete test & Maximise \\
4 & $\mathrm{R} 4$ & Compressive strength $\left(\mathrm{N} / \mathrm{mm}^{2}\right) 3$ days & Hardened concrete test & Maximise \\
5 & $\mathrm{R} 5$ & Compressive strength $\left(\mathrm{N} / \mathrm{mm}^{2}\right) 7$ days & Hardened concrete test & Maximise \\
6 & $\mathrm{R} 6$ & Compressive strength $\left(\mathrm{N} / \mathrm{mm}^{2}\right) 28$ days & Hardened concrete test & Maximise \\
7 & $\mathrm{R} 7$ & Splitting tensile strength $\left(\mathrm{N} / \mathrm{mm}^{2}\right) 28$ days & Hardened concrete test & Maximise \\
8 & $\mathrm{R} 8$ & Water absorption $(\%)$ & Hardened concrete test & Minimise \\
\hline
\end{tabular}

Table 3. Factors and their levels.

\begin{tabular}{|c|c|c|c|c|c|}
\hline \multirow[b]{2}{*}{ Factors } & \multirow[b]{2}{*}{ Definition } & \multicolumn{2}{|c|}{ Bounds $\pm(\%)$} & \multicolumn{2}{|c|}{ Bounds* (kg) } \\
\hline & & First level & Second level & First level & Second level \\
\hline FRP & Flame-retardant polyester & 10 & 15 & 70 & 105 \\
\hline CDP & Cationic-dyeable polyester & 10 & 15 & 70 & 105 \\
\hline LMP & Polyester has low melt point & 10 & 15 & 70 & 105 \\
\hline
\end{tabular}

\pm defined replaced to fine aggregate.

*Defined according to preliminary test results.

12350-2 [31] and EN 12390-7 [32]. Eight performance criteria and their desired properties are presented in table 2.

\subsection{Definition of factors and experiment conditions}

Three factors that each has two mix levels affect the POREC quality were determined as flame retardant, cationic dyeable and polyester with the LMP amount taking into account preliminary experiments. Polyester aggregates FRP, CDP and LMP were used instead of fine aggregate (table 3 ). In all experiments for $1 \mathrm{~m}^{3}$ concrete; amount of cement, amount of fly ash, water to binder (cement and fly ash) ratio, super-plasticiser content defined for one hundred kilograms binder (SP), the percentage of fine aggregate to total aggregate ratio (FA), coarse aggregate (I) to total aggregate ratio (CA1) and coarse aggregate (II) to total aggregate ratio (CA2) are fixed at $450 \mathrm{~kg}, 120 \mathrm{~kg}, 0.45$, $1.25,60,20$ and 20 , respectively, considering preliminary test results.

\section{Full factorial design and effect analysis}

A $2^{3}$ full factorial design was chosen to implement the experiments in this study. In table 4, columns 2-4 represent the three control factors and their codified levels. Columns 5-7 show uncodified levels belonging to factors. Columns 8 and 10 illustrate the unit weight of fresh and dry concrete.

Table 4. Full factorial design and sample properties.

\begin{tabular}{|c|c|c|c|c|c|c|c|c|c|}
\hline \multirow[b]{2}{*}{$\begin{array}{l}\text { Exp. } \\
\text { no. }\end{array}$} & \multicolumn{3}{|c|}{ Factors (coded) } & \multicolumn{3}{|c|}{ Factors (uncodified) } & \multicolumn{3}{|c|}{ Properties of sample } \\
\hline & FRP & $\mathrm{CDP}$ & LMP & $\begin{array}{l}\text { FRP } \\
(\mathrm{kg})\end{array}$ & $\begin{array}{l}\mathrm{CDP} \\
(\mathrm{kg})\end{array}$ & $\begin{array}{l}\mathrm{LMP} \\
(\mathrm{kg})\end{array}$ & $\begin{array}{l}\text { Unit weight of fresh } \\
\text { concrete }\left(\mathrm{kg} / \mathrm{m}^{3}\right)\end{array}$ & $\begin{array}{l}\text { Fresh concrete } \\
\text { temperature }{ }^{\circ} \mathrm{C}\end{array}$ & $\begin{array}{l}\text { Unit weight of dry } \\
\text { concrete }\left(\mathrm{kg} / \mathrm{m}^{3}\right)\end{array}$ \\
\hline MR0* & - & - & - & - & - & - & 2419 & 23.0 & 2370 \\
\hline MR1 & -1 & -1 & -1 & 70 & 70 & 70 & 2170 & 20.2 & 2150 \\
\hline MR2 & 1 & -1 & -1 & 105 & 70 & 70 & 2147 & 21.1 & 2107 \\
\hline MR3 & -1 & 1 & -1 & 70 & 105 & 70 & 2284 & 21.3 & 2254 \\
\hline MR4 & 1 & 1 & -1 & 105 & 105 & 70 & 2103 & 20.6 & 2070 \\
\hline MR5 & -1 & -1 & 1 & 70 & 70 & 105 & 2124 & 26.2 & 2081 \\
\hline MR6 & 1 & -1 & 1 & 105 & 70 & 105 & 2093 & 26.1 & 2068 \\
\hline MR7 & -1 & 1 & 1 & 70 & 105 & 105 & 1770 & 21.2 & 1746 \\
\hline MR8 & 1 & 1 & 1 & 105 & 105 & 105 & 2003 & 20.2 & 1969 \\
\hline
\end{tabular}

*MR0: Reference concrete. 
Table 5. Quantity of mixture for all experiments $\left(1 \mathrm{~m}^{3}\right)$.

\begin{tabular}{lcccccccrrrr}
\hline $\begin{array}{l}\text { Exp. } \\
\text { no. }\end{array}$ & $\begin{array}{c}\text { Cement } \\
(\mathrm{kg})\end{array}$ & $\begin{array}{c}\text { Fly ash } \\
(\mathrm{kg})\end{array}$ & $\begin{array}{c}\text { Water } \\
(\mathrm{kg})\end{array}$ & $\begin{array}{c}\text { SP } \\
(\mathrm{kg})\end{array}$ & $\begin{array}{c}\text { FA } \\
(\mathrm{kg})\end{array}$ & $\begin{array}{c}\text { CA1 } \\
(\mathrm{kg})\end{array}$ & $\begin{array}{l}\text { CA2 } \\
(\mathrm{kg})\end{array}$ & $\begin{array}{r}\text { FRP } \\
(\mathrm{kg})\end{array}$ & $\begin{array}{r}\text { CDP } \\
(\mathrm{kg})\end{array}$ & $\begin{array}{c}\text { LMP } \\
(\mathrm{kg})\end{array}$ & $\begin{array}{c}\text { Total polyester } \\
(\mathrm{kg})\end{array}$ \\
\hline *MR0 & 450 & 120 & 219.6 & 5.98 & 898 & 305 & 305 & 0 & 0 & 0 & 0 \\
MR1 & 450 & 120 & 219.6 & 5.98 & 449 & 305 & 305 & 70 & 70 & 70 & 210 \\
MR2 & 450 & 120 & 219.6 & 5.98 & 374 & 305 & 305 & 105 & 70 & 70 & 245 \\
MR3 & 450 & 120 & 219.6 & 5.98 & 374 & 305 & 305 & 70 & 105 & 70 & 245 \\
MR4 & 450 & 120 & 219.6 & 5.98 & 299 & 305 & 305 & 105 & 105 & 70 & 280 \\
MR5 & 450 & 120 & 219.6 & 5.98 & 374 & 305 & 305 & 70 & 70 & 105 & 245 \\
MR6 & 450 & 120 & 219.6 & 5.98 & 299 & 305 & 305 & 105 & 70 & 105 & 280 \\
MR7 & 450 & 120 & 219.6 & 5.98 & 299 & 305 & 305 & 70 & 105 & 105 & 280 \\
MR8 & 450 & 120 & 219.6 & 5.98 & 225 & 305 & 305 & 105 & 105 & 105 & 315 \\
\hline
\end{tabular}

*MR0: Reference concrete.

Table 6. Experimental results.

\begin{tabular}{lccccccc}
\hline Exp. no. & $\mathrm{R} 1(\mathrm{~W} / \mathrm{m} * \mathrm{~K})$ & $\mathrm{R} 2(\mathrm{ohm} * \mathrm{~m})$ & $\mathrm{R} 3(\mathrm{~cm})$ & $\mathrm{R} 4\left(\mathrm{~N} / \mathrm{mm}^{2}\right)$ & $\mathrm{R} 5\left(\mathrm{~N} / \mathrm{mm}^{2}\right)$ & $\mathrm{R} 6\left(\mathrm{~N} / \mathrm{mm}^{2}\right)$ & $\mathrm{R} 7\left(\mathrm{~N} / \mathrm{mm}^{2}\right)$ \\
\hline *MR0 & 1.65 & 202.650 & 17 & 42.30 & 47.62 & 58.16 & 3.96 \\
MR1 & 1.06 & 327.973 & 16 & 30.97 & 39.36 & 41.72 & 1.85 \\
MR2 & 1.29 & 525.244 & 17 & 33.58 & 34.97 & 36.00 & 0.93000 \\
MR3 & 1.60 & 583.216 & 17 & 31.93 & 36.40 & 34.25 & 2.45 \\
MR4 & 1.39 & 605.628 & 17 & 31.69 & 33.98 & 34.00 & 1.84955 \\
MR5 & 1.44 & 528.737 & 18 & 33.37 & 34.99 & 37.67 & 1.84 \\
MR6 & 1.53 & 494.550 & 17 & 31.14 & 32.47 & 33.14 & 1.32330 \\
MR7 & 1.11 & 476.613 & 16 & 34.35 & 35.80 & 37.09 & 1.82 \\
MR8 & 1.09 & 638.126 & 20 & 32.12 & 33.10 & 33.77 & 1.72 \\
\hline
\end{tabular}

*MR0: Reference concrete.

Fresh concrete temperature of POREC in all experiments has been also given in column 9. The actual contents of all the ingredients per cubic meter of concrete for all experimental runs can be seen in table 5 .

The experimental results obtained by full factorial design of experiments are illustrated in table 6. All main and Pareto effects analysis were computed by MINITAB $^{\circledR}$ version 17.

\subsection{POREC properties}

When Pareto effect plots for thermal conductivity are analyzed, it is seen that the interaction between cationic dyeable and polyester with the low melt amount has the highest variability on the thermal conductivity of POREC (figure 2a).

A large percentage of total variability in thermal conductivity is due to these polyesters. To obtain concrete with the desired thermal insulation properties, cationic dyeable and polyester with the low melt should be used together (figure 2a). A large percentage of total variability in electrical resistivity is due to the CDP (figure $2 b$ ). Therefore, it can be said that the CDP is the highest corrosion-resistance product in the most common commercial polyesters. The most influential factor on slump flow value is a three-way interaction term between the FRP, CDP and LMP
(Figure 2c). The most influential factor on the 28-day compressive strength was determined as the FRP. The 28-days splitting tensile strength and the percentage of water adsorption are importantly influenced by the interaction term between FRP, CDP and LMP, respectively (figure $2 \mathrm{~d}$ to $\mathrm{f}$ ).

The response of thermal conductivity is importantly influenced by the antagonistic impact of linear terms of ratio of CDP and LMP, influenced synergistically by the FRP amount (figure 3a). It can be interpreted in the main effect plot for electrical resistivity that this property of POREC increased with increasing amount of all polyesters, which has been used in this study (figure $3 b$ ). Electrical resistivity is importantly influenced by the synergistic impact of interaction terms belonging to the ratio of flame retardant, cationic dyeable and polyester with the low melt amount (figure 3b).

The slump flow is importantly influenced by the synergistic impact of linear terms belonging to the ratio of flame retardant, cationic dyeable and polyester with the low melt amount (figure 3c) [33]. The 3-day compressive strength is importantly influenced by the antagonistic impact of linear terms belonging to the ratio of flame retardant, by the synergistic impact of linear terms of cationic dyeable and polyester with the low melt amount. It can be said that these polyesters could be used for early strength. 

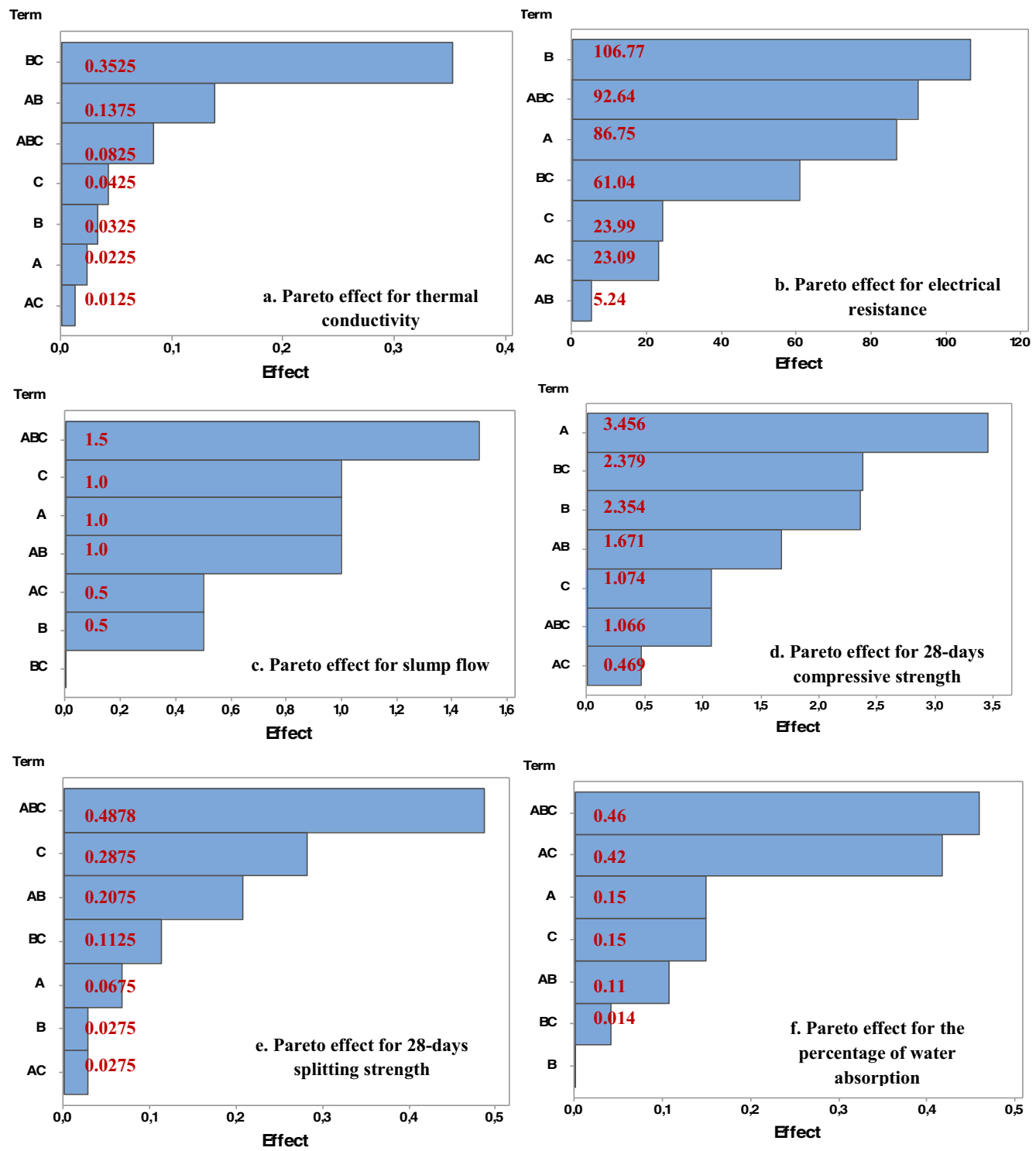

Figure 2. Effects Pareto for all responses, (A: Flame-retardant polyester, B: Cationic dyeable polyester, C: Polyester has low melt point).

However, all polyesters have negative effect on 7-day compressive strength. Similarly, 28-day compressive strength is significantly negatively affected with increasing all polyesters used in study (figure 3d). The 28-day splitting tensile strength is significantly affected by the antagonistic impact of linear terms of all polyester types used in this study (figure 3e) [33].

Slump flow is significantly influenced by the synergistic impact of linear terms of ratio of flame retardant, cationic dyeable and polyester with the low melt amount (figure 3c) [33]. The 3-day compressive strength is significantly influenced by the antagonistic impact of linear terms of ratio of flame retardant, by the synergistic impact of linear terms of cationic dyeable and polyester with the low melt amount. It can be said that these polyesters could be used for early strength. However, all polyesters have negative effect on 7-day compressive strength.
Similarly, the 28-days compressive strength is significantly negatively affected with increasing all polyesters used in study (figure 3d). The 28-days splitting tensile strength is significantly affected by the antagonistic impact of linear terms of all polyester types used in this study (figure 3e) [33].

Water absorption is significantly influenced by the synergetic impact of linear terms of flame retardant and polyester with the low melt point. However, the percentage of water absorption has not been changed with increasing the cationic polyester amount (figure 3f). Water absorption is highly related to capillary pores in mortar of concrete. The concrete components influence the capillary pores and water absorption of concrete. Therefore, it can be said that CDP is the highest water-repelling product in the most common commercial polyesters. Low absorption is also an 

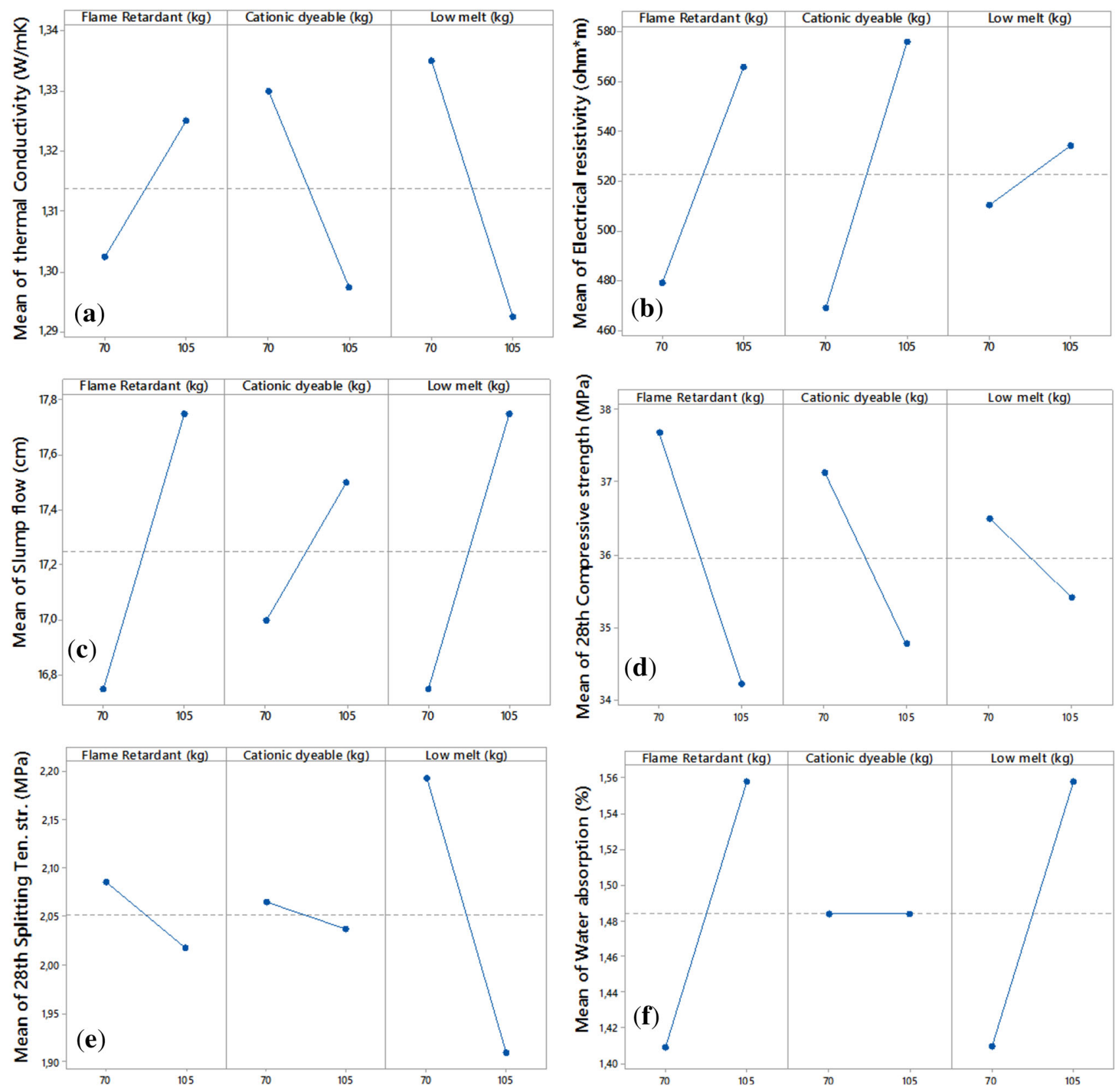

Figure 3. Main effect plot for all responses (A: Flame-retardant polyester, B: Cationic dyeable polyester, C: Polyester has low melt point).

indication of good compaction achieved by the concrete with CDP.

\subsection{Morphologic analysis}

Scanning electron microscopy (SEM) can be used to analyze the concrete and polyester compactness and homogeneity, cavernous in structure and adhesion to materials $[24,34,35]$. SEM image of polyester aggregate-filled concrete can be seen in figure 4 . The formation of a strong transition zone between plastic aggregate and cement paste shows that there is a good adhesion between these materials $[24,35,36]$. When the part taken from the polyester-reinforced concrete is examined, it is seen that the three polyester types are held well on to the concrete (figure 4a). Observation of the transition zone between cement paste and polyester aggregate is an important sign that these polyester aggregates are held in the cement paste (figure 4b). Moreover, polyester surface was covered with densely hydrated cement matrix in POREC (figure $4 \mathrm{~b}$ ). It is seen that the polyesters provide a good adhesion with the cement paste and fly ash (figure $4 \mathrm{~b}$ and $4 \mathrm{c}$ ). The $\mathrm{C}-\mathrm{S}-\mathrm{H}$ gel 


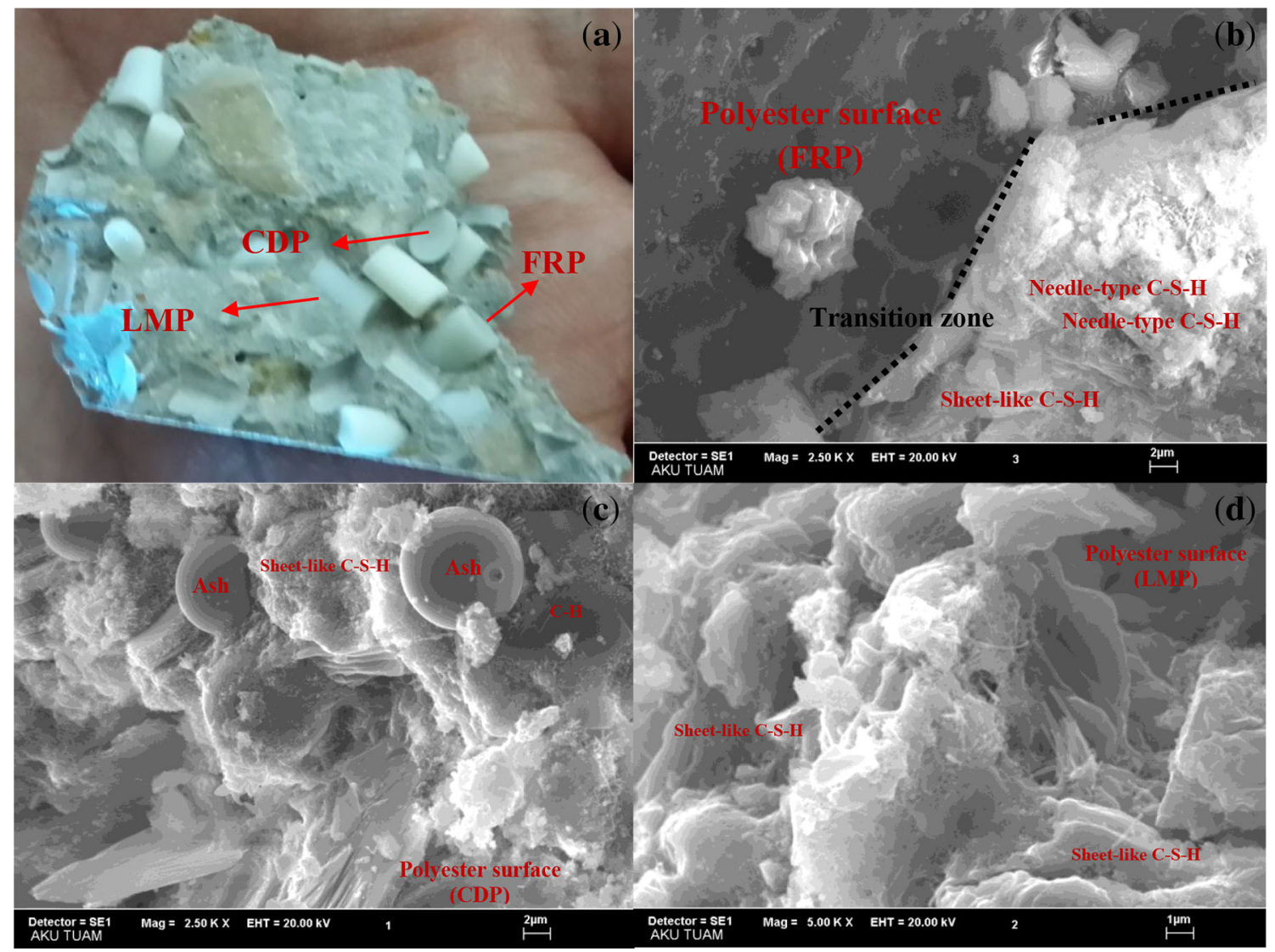

Figure 4. SEM images of polyester-reinforced concrete composites (a) a part of crushed POREC, (b) FRP, (c) CDP and (d) LMP.

is related to the durability properties of hydrated cementbased materials [37]. It was seem that the C-S-H gel is the predominant structure in the SEM images. So it is thought that the concrete will have higher mechanical strength in the future (figure $4 b-c-d$ ). FRP has half-open porous surface texture, while CDP and LMP have a rough surface, as clearly seen from the SEM images. These half-open porous and rough surface textures increased the interconnection of cement matrix and polyesters. It may be concluded that the surface texture of polyesters increases the holding of hydrated cement matrix or mortar on the polymer (figure $4 \mathrm{a}-\mathrm{d}$ ). The obtained polyester-reinforced concrete composite, which has got 28-days compressive strength at 33.77 MPa value, is suitable for $\mathrm{C} 25 / 30$ concrete class. The sheet-like and needle-type $\mathrm{C}-\mathrm{S}-\mathrm{H}$ gel indicates that concrete will gain compressive strength by the time of process. When analyzing the SEM image of POREC, there are not seen as pores, cracks, delaminations, deformations and micro voids. Benefiting from SEM analysis, it can be inferred that there is a compact and homogeneous structure between polyester fillers and concrete paste (Figure 4a-d).

\subsection{Improvement ratios in the POREC properties}

The thermal conductivity value of the POREC decreased from $1.65 \mathrm{~W} / \mathrm{m} * \mathrm{~K}$ to $1.09 \mathrm{~W} / \mathrm{m} * \mathrm{~K}$ with the addition of

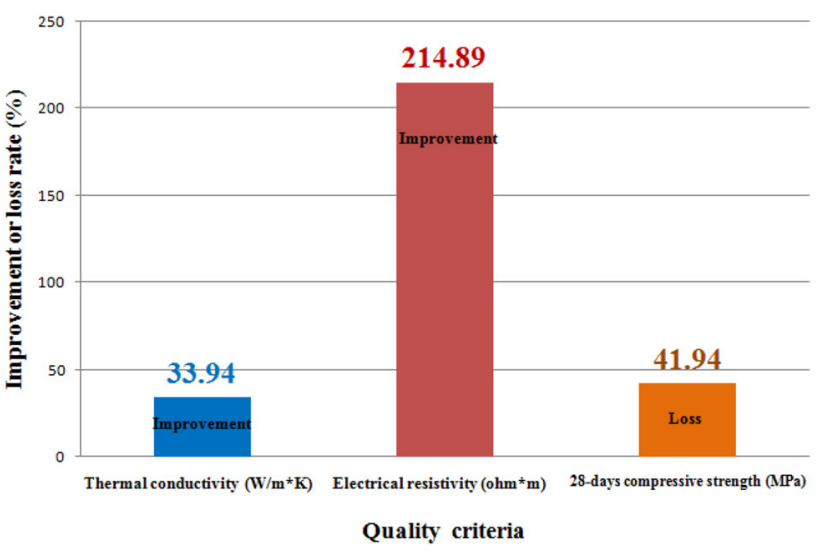

Figure 5. Improvement or loss rate $(\%)$ for the selected quality criteria.

$105 \mathrm{~kg}$ of each polyester type compared to the reference concrete. The electrical resistivity value of the POREC increased from $202.65 \mathrm{ohm} * \mathrm{~m}$ to $638.13 \mathrm{ohm} * \mathrm{~m}$ with the addition of $105 \mathrm{~kg}$ of each polyester type compared to the reference concrete. Meanwhile, the 28-day compressive strength of the POREC decreased from 58.16 MPa to $33.77 \mathrm{MPa}$. Although there is a decrease with $41.94 \%$ [(58.16-33.77)/(58.16)] (please see table 4; M8-numbered mixture) by the reference concrete (table 4; M0-numbered mixture) at 28-day compressive strength, a recovery with 
$33.94 \%[(1.65-1.09) /(1.65)]$ is obtained at thermal conductivity value and an improvement ratio with $214.89 \%$ $[(638.13-202.65) /(638.13)]$ is obtained at electrical resistance value (please see table 4; M8-numbered mixture). Improvement rates for POREC compared to the reference concrete have been given in figure 5 .

\section{Conclusions}

A full factorial-based design of experiment approach has been first used to analyze the polyester-reinforced composite concrete's properties systematically. Both the main and Pareto effects on the selected responses such as the thermal conductivity, electrical resistivity, slump flow, 3-day compressive strength, 7-day compressive strength, 28-day compressive strength, 28-day splitting tensile strength and the percentage of water absorption have been analyzed statistically via the full factorial design.

The effect of the most influential factors on the polyester-reinforced composite concrete's thermal conductivity has been determined as the interaction between the cationic dyeable and low-melt-point polyester. These two polyestermixed concrete composites are suitable for the production of thermal insulating concrete. Moreover, it is concluded that the CDP has the highest electrical resistance, in other words, corrosion resistance, product among polyesters that are used in this study. Furthermore, the CDP and polyester with the low melt point increase with the 3-day compressive strength. Considering these results, the CDP, which has high thermal, water and corrosive resistance, is found to be a more attractive polyester.

Another remarkable result is that despite the lack of individual effect on responses, polyester fillers have a significant effect on responses as two or three interactions. To illustrate, the CDP and polyester with low-melt point have a little individual effect on thermal conductivity. However, they have significant reducing effect on thermal conductivity (figure 2) together. This result demonstrates that an experimental design should be used to analyze quality criteria that contradict each other.

The recovery rate of $33.94 \%$ in the thermal conductivity and $214.89 \%$ in the electrical resistivity of polyester-reinforced concrete composites has been obtained with a 28-day compressive strength loss of $41.94 \%$ according to the reference concrete (polyesters have not been used in concrete) in the full factorial design application. This improvement in the thermal conductivity value is important for the building sector, which is the largest energy consumer in terms of energy saving and reduction of the carbon emissions. The improvement ratio in the electrical resistivity value is quite remarkable to obtain such concrete that has high corrosion endurance compared to the reference concrete.

The polyester-reinforced concrete composite has $1.09 \mathrm{~W} / \mathrm{m} * \mathrm{~K}$ thermal conductivity value and $638.13 \mathrm{ohm} * \mathrm{~m}$ electrical resistivity value, which is obtained with full factorial design study, is included in C $25 / 30$ compressive strength class as it has 28-day compressive strength at $33.77 \mathrm{MPa}$ value. These results indicate that the polyester-reinforced concrete composites are quite effective for achieving thermal and corrosion resistance concrete with an acceptable compressive strength loss.

\section{References}

[1] Xu F, Zhou M, Chen J and Ruan S 2014 Mechanical performance evaluation of polyester fiber and SBR latex compound-modified cement concrete road overlay material. Constr. Build. Mater. 63: 142-149. https://doi.org/10.1016/j. conbuildmat.2014.04.054

[2] Seleem H E H 2006 The effect of inorganic fillers on the mechanical and thermal properties of polyester. Polym. Plast. Technol. Eng. 45(5): 585-590. https://doi.org/10.1080/ 03602550600553754

[3] Heidari-Rarani M, Aliha M R M, Shokrieh M M and Ayatollahi M R 2014 Mechanical durability of an optimized polymer concrete under various thermal cyclic loadings-An experimental study. Constr. Build. Mater. 64: 308-315. https://doi.org/10.1016/j.conbuildmat.2014.04.031

[4] Zhao L, Guo X, Ge C, Li Q, Guo L, Shu X and Liu J 2016 Investigation of the effectiveness of PC@GO on the reinforcement for cement composites. Constr. Build. Mater. 113: 470-478. https://doi.org/10.1016/j.conbuildmat.2016.03.090

[5] Martínez-Barrera G, Menchaca-Campos C and Gencel O 2013 Polyester polymer concrete: Effect of the marble particle sizes and high gamma radiation doses. Constr. Build. Mater. 41: 204-208. https://doi.org/10.1016/j.conbuildmat. 2012.12.009

[6] Rohatgi P K, Matsunaga T and Gupta N 2009 Compressive and ultrasonic properties of polyester/fly ash composites. $J$. Mater. Sci. 44(6): 1485. https://doi.org/10.1007/s10853-0083165-1

[7] Saribiyik M, Piskin A and Saribiyik A 2013 The effects of waste glass powder usage on polymer concrete properties. Constr. Build. Mater. 47: 840-844

[8] Shokrieh M M, Rezvani S and Mosalmani R 2015 A novel polymer concrete made from fine silica sand and polyester. Mech. Compos. Mater. 51(5): 571-580. https://doi.org/10. 1007/s11029-015-9528-1

[9] Ribeiro M, Reis J, Ferreira A and Marques A 2003 Thermal expansion of epoxy and polyester polymer mortars-plain mortars and fibre-reinforced mortars. Polym. Test. 22(8): 849-857.

[10] Ribeiro M, Tavares C and Ferreira A 2002 Chemical resistance of epoxy and polyester polymer concrete to acids and salts. J. Polym. Eng. 22(1): 27-44

[11] Siddique R, Kapoor K, Kadri E H and Bennacer R 2012 Effect of polyester fibres on the compressive strength and abrasion resistance of HVFA concrete. Constr. Build. Mater. 29: 270-278. https://doi.org/10.1016/j.conbuildmat.2011.09.011

[12] Abu-Jdayil B, Mourad A H and Hussain A 2016 Thermal and physical characteristics of polyester-scrap tire composites. Constr. Build. Mater. 105: 472-479. https://doi.org/10.1016/ j.conbuildmat.2015.12.180 
[13] Nabinejad O, Sujan D, Rahman M E and Davies I J 2015 Effect of oil palm shell powder on the mechanical performance and thermal stability of polyester composites. Mater. Des. 65: 823-830. https://doi.org/10.1016/j.matdes.2014.09. 080

[14] Jamshidi M and Pourkhorshidi A R 2012 Modified polyester resins as an effective binder for polymer concretes. Mater. Struct. 45(4): 521-527. https://doi.org/10.1617/s11527-0119779-9

[15] Adeosun S O, Gbenebor O P, Akpan E I and Udeme F A 2016 Influence of organic fillers on physicochemical and mechanical properties of unsaturated polyester composites. Arabian J. Sci. Eng. 41(10): 4153-4159. https://doi.org/10. 1007/s13369-016-2120-8

[16] Wang B, Qian T, Zhang Q, Zhan X and Chen F 2016 Heat resistance and surface properties of polyester resin modified with fluorosilicone. Surf. Coat. Technol. 304: 31-39. https:// doi.org/10.1016/j.surfcoat.2016.06.075

[17] Lin J H, Hsieh J C, Lin J Y, Lin M C and Lou C W 2014 Polyester/low melting point polyester nonwoven fabrics used as soilless culture mediums: effects of the content of low melting point polyester fibers. In: Applied Mechanics and Materials 2014, pp. 49-52. Trans Tech Publ 10.4028/ https:// doi.org/10.4028/www.scientific.net/AMM.457-458.49

[18] Carosio F, Di Blasio A, Cuttica F, Alongi J and Malucelli G 2014 Flame retardancy of polyester and polyester-cotton blends treated with caseins. Ind. Eng. Chem. Res. 53(10): 3917-3923

[19] Zhao M L, Li F X, Yu J Y and Wang X L 2014 Preparation and characterization of poly (ethylene terephthalate) copolyesters modified with sodium-5-sulfo-bis-(hydroxyethyl)isophthalate and poly (ethylene glycol). J. Appl. Polym. Sci. 131(3): 39823

[20] TS EN ISO 1183-1 2015 Plastics-Methods for determining the density of non-cellular plastics-Part 1: Immersion method, liquid pyknometer method and titration method. p. 22.

[21] TS EN ISO 527-1 2015 Plastics-Determination of tensile properties-Part 1: General principles. p. 33

[22] Bounouri Y, Berkani M, Zamouche A and Rycerz L 2017 Optimization and modeling of synthesis parameters of neodymium(III) bromide by dry method using full factorial design analysis. Arabian J. Chem. https://doi.org/10.1016/j. arabjc.2017.05.003

[23] Cintas P G, Almagro L M and Llabrés X T M 2012 Pareto charts and cause-effect diagrams. In: Industrial Statistics with Minitab. Wiley, pp. 31-36

[24] Şimşek B and Uygunoğlu T 2016 Multi-response optimization of polymer blended concrete: A TOPSIS based Taguchi application. Constr. Build. Mater. 117: 251-262. https://doi. org/10.1016/j.conbuildmat.2016.05.027

[25] Huang J, Lv H, Gao T, Feng W, Chen Y and Zhou T 2014 Thermal properties optimization of envelope in energy-saving renovation of existing public buildings. Energy Build. 75: 504-510. https://doi.org/10.1016/j.enbuild.2014.02.040

[26] ASTM C1113/C1113M-09 2013 Standard test method forthermal conductivity of refractories by hot wire (Platinum Resistance Thermometer Technique)(American Society for Testing and Materials, West Conshohocken, PA)

[27] Wang H, Yang J, Liao H and Chen X 2016 Electrical and mechanical properties of asphalt concrete containing conductive fibers and fillers. Constr. Build. Mater. 122: 184-190. https://doi.org/10.1016/j.conbuildmat.2016.06.063

[28] Lübeck A, Gastaldini A L G, Barin D S and Siqueira H C 2012 Compressive strength and electrical properties of concrete with white Portland cement and blast-furnace slag. Cem. Concr. Compos. 34(3): 392-399. https://doi.org/10. 1016/j.cemconcomp.2011.11.017

[29] TS EN 2010 Testing Hardened Concrete-Part 3, Compressive Strength of Test Specimens. p. 21. Ankara

[30] TS EN 2010 Testing Hardened Concrete-Part 6, Determination of Splitting Tensile Strength of Concrete Specimens. p. 13. Ankara

[31] TS EN 2010 Testing fresh concrete-Part 5, Flow table test. p. 9. Ankara

[32] TS EN 123902010 Testing Hardened Concrete-Part 7, Density of Hardened Concrete, p. 12. Ankara.

[33] Şimşek B, İç Y T and Şimşek E H 2016 A RSM-based multiresponse optimization application for determining optimal mix proportions of standard ready-mixed concrete. Arabian J. Sci. Eng. 41(4): 1435-1450. https://doi.org/10.1007/ s13369-015-1987-0

[34] Marzouk O Y, Dheilly R M and Queneudec M 2007 Valorization of post-consumer waste plastic in cementitious concrete composites. Waste Manage. 27(2): 310-318. https:// doi.org/10.1016/j.wasman.2006.03.012

[35] Gu L and Ozbakkaloglu T 2016 Use of recycled plastics in concrete: a critical review. Waste Manage. 51: 19-42. https:// doi.org/10.1016/j.wasman.2016.03.005

[36] Fraj A B, Kismi M and Mounanga P 2010 Valorization of coarse rigid polyurethane foam waste in lightweight aggregate concrete. Constr. Build. Mater. 24(6): 1069-1077

[37] Goñi S, Frias M, Vegas I, García R and de la Villa R V 2012 Quantitative correlations among textural characteristics of $\mathrm{C}-\mathrm{S}-\mathrm{H}$ gel and mechanical properties: case of ternary Portland cements containing activated paper sludge and fly ash. Cem. Concr. Compos. 34(8): 911-916. https://doi.org/10. 1016/j.cemconcomp.2012.05.002 